\title{
Does Mathematical Anxiety Differ Cross-Culturally?
}

\author{
Jennifer L. Brown ${ }^{1} \oplus$, Myriam Ortiz-Padilla ${ }^{2} \odot$ and Roberto Soto-Varela ${ }^{3} \odot$ \\ ${ }^{1}$ Department Education and Health Professions, University of Columbus State, USA \\ ${ }^{2}$ Department of Legal and Social Sciences, University of Simón Bolívar, Colombia \\ ${ }^{3}$ Department of Education, University of Alfonso X el Sabio, Spain
}

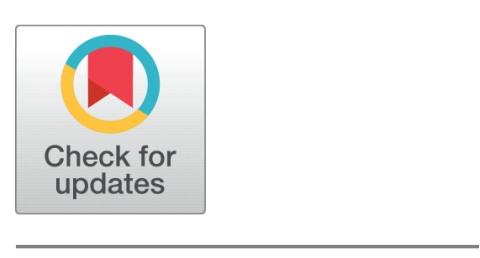

Received 2019-08-01

Revised 2019-09-06

Accepted 2019-10-21

Published 15-01-2020

\section{Corresponding Author}

Jennifer L. Brown,

brown_jennifer2@columbusstate. edu

Columbus State University 4225 University Avenue Columbus, Georgia 31907

DOI https://doi.org/10.7821/

naer.2020.1.464

Pages: 126-136

Distributed under

Creative Commons CC BY 4.0

Copyright: ( ) The Author(s)

\section{ABSTRACT}

Mathematics constitutes a foundation in the training of engineering students because their competence in this reasoning will be utilised as a tool for the resolution of real problems when inserted in the productive sector and throughout their professional life. The purpose of this causal comparative research study was to determine the difference in learning math anxiety and math evaluation anxiety for engineering students at two universities with different cultural backgrounds. The sample included 20 engineering students from the south-eastern United States and 88 engineering students from Colombia. The English and Spanish version of the AMAS, which contained nine items was divided into two subscales, used to collect data. A series of two-way factorial ANOVAs were conducted to answer the research questions that are related to cultural background, gender and the interaction effect between cultural group and gender. The results indicated there was a statistically significant difference in learning maths anxiety when comparing the two cultures.

\section{Keywords MATHEMATICAL ANXIETY, POST-SECONDARY, CROSS-CULTURAL,} MATH EVALUATION ANXIETY

\section{INTRODUCTION}

Nowadays the learning of mathematics is increasingly important as the National Council of Teachers of Mathematics (NCTM., 2003) tells us because they argue that in a changing world those who understand, can do and use mathematics, will have more and more opportunities and options to determine their future. This is due to the highly digitalized society in which we are framed, in which it is seen more as a necessity than an option. Mathematics is therefore considered a fundamental basis for learning, as it corresponds to an area of knowledge in which we develop daily. However, most people fail to develop mathematical ability at an optimal level; some grow disinterest in this competence, because dealing with mathematical situations can generate frustration, despair, unpleasant states and negative emotions.

These statements are evidenced by the fact that both teachers and non-teachers hear students grumble about their lack of enthusiasm for the subject, its difficulty, how bored they are, and a number of complaints in this regard.

\section{OPEN ACCESS}


It is recognized that there are many factors that can play an important role in the performance of mathematics learning in young engineering students who attend universities, especially the socio-cultural factor that includes the particular characteristics of educational institutions, financial resources, the organizational quality of the faculty, class schedules, group settings, home education, the socioeconomic level of the family, among others (Garbanzo-Vargas, 2016); to the way in which cultural practices have shaped students' way of thinking, stereotypes, stigmas and other related aspects, as opposed to a phenomenon such as mathematical learning and mathematics in general (Agredo, Ávila Díaz, \& Grisales, 2014).

In this way, culture could become a differentiating element when approaching this type of knowledge.

When talking about affective factors, perhaps one of the most relevant is the anxiety towards mathematics, understood as the unpleasant state of mind characterized by anxiety, fear and concern when facing situations where they are required to perform in mathematics. According to Gómez-Chacón (2010), there are many studies in which the academic mathematical performance of students is associated with that anxiety and fear.

In this regard, Marshall (2000) indicates that mathematical anxiety is an important, yet not a well understood reality for students and an issue carelessly managed by some teachers.

Mathematical anxiety is a topic that has been of interest to the research community for more than 40 years and it is so important that it still remains a topic of great relevance to the community. As evidenced in the incorporation into the PISA 2003 study (Delgado, Espinoza, \& Fonseca, 2017) carried out in 40 countries, whose results reflect that a large number of the 15-year-old students who participated in the study presented mathematical anxiety which is a serious issue to take into account. (Pérez-Tyteca, 2012).

\section{THEORETICAL FRAMEWORK}

Mathematics constitutes a foundation in the training of engineers because their competence in this reasoning will be utilised as a tool for the resolution of real problems when inserted in the productive sector and during their professional life (Suárez, Perez-Tyteca, \& Monje, 2018). There are a multitude of factors that play an important role in the performance of mathematics learning in the young engineering students at the university level: Social, Cognitive, Cultural, and Emotional factors. Within the emotional-affective factors, anxiety towards mathematics has probably become the most important. This anxiety is defined as that "unpleasant feeling of tension and anxiety that hinder the ability to deal with numbers and mathematics in a variety of situations" (O'Leary, Fitzpatrick, \& Hallett, 2017, p.1) and that involves three types of components: affective, cognitive and behavioural (GarcíaSantillán, Martínez-Rodríguez, \& Santana, 2018). This type of anxiety is then defined very specifically associated with the learning of mathematical contents. Some of the behavioural components in which this type of emotion takes place are maladaptive behaviours, nonattendance to classes, and avoidance of mathematics courses, among others. As far as the associated cognitive aspects are concerned, we find intrusive and inhibitory thoughts can 
arise in the individual in a disruptive and involuntary way, with outbreaks of hopelessness, worry, fear of failure, associated therefore with negative emotions (Mehdinezhad \& Bamari, 2015). These types of irrelevant thoughts seize the consciousness which cause a decrease in the ability to memorize because it has to deal with and manage these thoughts triggering a decrease in the effectiveness and efficiency of the mathematical task (Jácquez, 2018; JusticiaGaliano et al., 2016).

The effects of anxiety are not limited to physical symptoms, as has been investigated as this anxiety may affect the performance of students in classes, assessments, standardized tests and even their decisions about their career paths to follow (Maloney, Schaeffer, \& Beilock, 2013). Moreover, these feelings influence the self-belief of the student negatively, which affects the confidence of students to learn mathematics. Research has shown that students who tend to be more anxious about maths, develop less confidence, have poor belief in their ability to cope with the task, and feel poorly skilled (Calvo, Cascante, Valdés-Ayala, \& Quesada, 2017)-

In the field of mathematics education, mathematical anxiety has become important as there are several research papers that indicate that mathematical anxiety may be the cause of learning difficulties regardless of the level of education. Cerda, Ruiz, Casas, Rey, and Pérez (2016) state that some emotions are activated at the moment of learning and that they play a very important role in the development of the required cognitive tasks. Thus, positive emotions such as interest, curiosity and joy lead success while emotions like anxiety, hopelessness or fear can cause the blockage of these processes and lead to failure or mismatch in the academic processes, as they do not allow a smooth processing of information.

In this sense, efforts must be made to understand behaviour in each region, country, and educational institution in order to be able to develop relevant actions that improve student performance in mathematics and other quantitative disciplines (Eccius-Wellmann, LaraBarragán, Martschink, \& Freitag, 2017).

Many studies indicate an inverse relationship between mathematical anxiety in mathematical performance (Isiksal, Curran, Koc, \& Askun, 2009; Rodic et al., 2018). Other research indicates a bidirectional relationship, meaning mathematical anxiety and the academic performance can influence each other and become a vicious circle difficult to break (Carey, Hill, Devine, \& Szücs, 1987). As for the relationship of mathematical anxiety and gender, conclusive studies are not recognized. Pérez-Tyteca, Castro, Rico, and Castro (2011) argue that females tend to suffer more mathematical anxiety than males by displaying more physical symptoms that could be more or less visible according to the situation (e.g., nerves and tension among others); therefore, there tends to be lower mathematical performance in this area, which leads to avoidance of quantitative courses and limits their future education and career options.

For example, in Mexico, men have seven more points than women in performance associated with this factor (García-Santillán et al., 2018).

Devine, Fawcett, Szücs, and Dowker (2012) found no differences between males and females for mathematical performance at the secondary level, but mathematical anxiety was a significant predictor of mathematical performance for females. Eccius-Wellmann et 
al. (2017) compared the profiles of mathematical anxiety among Mexican students and German students. The researchers found that German students present a higher level of mathematical anxiety than Mexican students; however, they did not find differences in gender. The implications of this study include these discrepancies which are associated with attitudes and beliefs towards mathematical learning and the same mathematics anxiety developed in each culture.

The recognition of mathematical anxiety has increased, including its value in international trials, such as PISA, which identifies that students who feel anxious who are not interested in their studies, have worse performance, and have less confidence in their skills to face mathematical problems in general and in this particular field (Pérez-Tyteca, Monk, \& Castro, 2013). For example, research conducted with the mathematics performance of Spanish students on the 2012 PISA tests revealed the risk of low mathematical performance varies depending on the level of mathematical anxiety present. Furthermore, it is recognized that a level of mathematical anxiety is required to mobilize the student to be efficient. If exceeded, this level may have a negative effect on their mathematical performance with the detriment that this implies for their academic future (Bauselas-Herrera, 2018).

As for the performance in mathematics of the Colombian students on international tests like PISA, in 2015, Colombia was ranked in position 61 among 70 participating countries with an average score of 390 (ICFES., 2017; Kastberg, Chan, Murray, \& Gonzales, 2016). The United States ranked 40th among 70 countries who participated in PISA with an average mathematics literacy score of 470 (ICFES., 2017; Kastberg et al., 2016). These results were no different compared to previous assessment years (i.e., 2012) (ICFES., 2017; Kastberg et al., 2016) . Moreover, $73.8 \%$ of Colombian students were placed in the lower quartile of performance. ICFES. (2017); Reali, Jimenez-Leal, Maldonado-Carreño, Devine, and Szücs (2016) point out that there are many factors that may be generating this low performance in Colombian students (e.g., great challenges facing the educational system related to the hiring of teachers, the subject of the evaluation, and the possibilities of improvement in the mathematical education), but these authors indicated mathematical anxiety could be an important factor that influences the PISA test scores.

To develop relevant actions to improve mathematical performance, is essential the creation of more effective educational environments that guarantee the development of the potential of all students in the area of mathematics a (Eccius-Wellmann et al., 2017; Maloney et al., 2013) and at the same time an improvement in the training of teachers with new and improved teaching techniques, since teachers are one of the basic pillars of a quality education. At the same time, several studies about the learning of mathematics have analysed the socio-cultural nature of it and have shown how much of the mathematical knowledge and the ways in which people approach it, are determined by the cultural practices of a social group and not only by the intellectual capacity of the subjects. Each culture has its own values and knowledge according to its own interests. In the same way each country has its own policies, organizes its educational system in a different way, chooses the contents, referents, models and its own guidelines according to the expected development and the expectations they generate. Therefore, considering that culture "is a set of knowledge and 
values, the result of the joint experience of a group of people who share vital or labour activities" (Gorgorió, Planas \& Vilella, 2000, p. 1), the way in which the students' learning will be generated in the field of mathematics will pass through this great cultural event and, to a great extent, many of the values, emotions, motivations, beliefs and their own conceptions, which may be referable to the ways in which their country and their specific cultures see the teaching and learning of this area of knowledge.

The present study sought to analyse the differences between the mathematical anxiety profiles of students in Colombia and those in the south-eastern United States. The purpose of this causal comparative research study was to determine the difference in learning maths anxiety and maths evaluation anxiety for engineering students at two universities with different cultural backgrounds as measured by Abbreviated Math Anxiety Scale (AMAS). Specifically, the study sought to answer the following research questions:

1. What is the difference in learning maths anxiety and maths evaluation anxiety for engineering students at two universities with different cultural backgrounds?

2. What is the difference in learning maths anxiety and maths evaluation anxiety for engineering students by gender?

3. Is there an interaction effect between cultural groups and gender for engineering students at two universities with different cultural backgrounds?

\section{METHODS}

\subsection{Participants}

Engineering students from two universities participated in this study. University A was located in the south-eastern United States, and University B was located in Colombia, which is in the northern part of South America. At University A, 85 engineering studies students were recruited for the study, and 27 students responded to the survey, which yielded a $31.76 \%$ response rate. After cleaning the data, 20 cases were deemed valid. Of these 20 cases, there were $16(80.0 \%)$ males and $4(20.0 \%)$ females. At University B, 92 engineering students were recruited for the study, and 88 students responded to the survey, which yielded a $95.6 \%$ response rate. Of these 88 cases, there were 58 (65.9\%) males and $30(34.1 \%)$ females.

\subsection{Data Collection}

At University A, a list of pre-engineering studies students (i.e., second, third, and fourth semesters in the program) was obtained from the Registrar's Office. Using that list, a series of three emails were sent to invite the students to participate in the study during the spring of 2017. The email included a brief overview of the study and an anonymous URL to access the online measure through Qualtrics, which was available through the university's technology department. After the participants selected the URL, they were directed to the informed consent. Upon agreement, the participants were able to complete the measure. At University $\mathrm{B}$, the official list was obtained of those students enrolled, who share initial training in 
the area of mathematics in the Engineering programs offered by the institution (i.e., System Engineer, Industrial Engineering, Market Engineering) in II and III semesters. Students were invited to participate in the study through an official approach supported by the directives of the program. After accepting participation, informed consent was given to the pencil and paper type questionnaire for their individual diligence.

The English version of the AMAS was developed and validated by Hopko, Mahadevan, Bare, and Hunt (2003). The Spanish version of the AMAS was translated and validated by J. L. Brown and Sifuentes (2016). The AMAS contained nine items, which were divided into two subscales, Learning Math Anxiety (LMA) and Math Evaluation Anxiety (MEA). The LMA subscale contained five items that measure anxiety when performing maths during instructional or studying time. The MEA subscale contained four items that measure maths anxiety during the administration of maths assessments. With all nine items, the response scale ranged from 1, Low Anxiety, to 5, High Anxiety. To determine the internal consistency among the subscale items, a series of reliabilities analyses were conducted through the software SPSS Statistics 24. For University A, the alpha coefficient for the LMA subscale was .868 , and the alpha coefficient for the MEA subscale was .701. For University $B$, the alpha coefficient for the LMA subscale was .793, and the alpha coefficient for the MEA subscale was .703. The results indicated that the coefficients were good based on Cohen and Swerdlik (2010) guidelines in order to develop the relevant statistics.

\section{RESULTS}

A two-way factorial ANOVA was conducted to determine the difference in LMA by cultural group and gender. Given the unequal groups, Levene's Test of Homogeneity was conducted to determine if there was equal variance among the groups. According to M. B. Brown and Forsythe (1974), if equal variance exists, the group size has minimal effect on the $F$ test. There was not a statistically significant difference in variance between the groups for LMA, meaning equal variance could be assumed $[F(3,104)=0.99 ; p=.40]$.

The mean LMA score for University A was 1.74 with a standard deviation of 0.92 . The mean LMA score for University B was 2.61 with a standard deviation of 0.94 . There was a statistically significant difference in LMA scores by cultural group, $F(3,104)=14.12$; $p=$ $.00 ; \eta_{p}{ }^{2}=.12$. The mean LMA score for all males was 2.40 with a standard deviation of 0.95 . The mean LMA score for all females was 2.55 with a standard deviation of 1.08. There was not a statistically significant difference in LMA scores by gender, $F(3,104)=0.26 ; p=.61$; $\eta_{p}{ }^{2}=.00$. Table 1 displays the means and standards deviations for LMA by cultural group and gender. Given the main effect of gender was not statistically significant, there was no interaction effect between cultural group and gender, $F(3,104)=0.99 ; p=.32 ; \eta_{p}^{2}=.01$.

A Two-Way Factorial ANOVA was conducted to determine the difference in MEA by cultural group and gender. Given the unequal groups, Levene's Test of Homogeneity was conducted to determine if there was equal variance among the groups. There was not a statistically significant difference in variance between the universities for MEA, meaning equal variance could be assumed $[F(3,104)=1.30 ; p=.28]$. 
Table 1 Means and Standard Deviations for LMA by Cultural Group and Gender

Males

Females

All

\begin{tabular}{lcccccc}
\hline Institution & $\mathrm{M}$ & $\mathrm{SD}$ & $\mathrm{M}$ & $\mathrm{SD}$ & $\mathrm{M}$ & $\mathrm{SD}$ \\
University A & 1.83 & 0.97 & 1.4 & 0.67 & 1.74 & 0.92 \\
University B & 2.56 & 0.88 & 2.70 & 1.04 & 2.61 & 0.94 \\
All & 2.40 & 0.95 & 2.55 & 1.08 & 2.44 & 0.99 \\
\hline
\end{tabular}

The mean MEA score for University A was 3.29 with a standard deviation of 0.95 . The mean MEA score for University B was 3.65 with a standard deviation of 0.92 . There was not a statistically significant difference in MEA scores by cultural group, $F(3,104)=2.77 ; p=$ $.07 ; \eta_{p}{ }^{2}=.03$. The mean MEA score for all males was 3.49 with a standard deviation of 0.99 . The mean MEA score for all females was 3.79 with a standard deviation of 0.77 . There was not a statistically significant difference in MEA scores by gender, $F(3,104)=0.02 ; p=.89$; $\eta_{p}{ }^{2}=.00$. Table 2 displays the means and standards deviations for MEA by cultural group and gender. Given that the main effect of gender was not statistically significant, there was no interaction effect between cultural group and gender, $F(3,104)=1.33 ; p=.25 ; \eta_{p}{ }^{2}=.01$.

Table 2 Means and Standard Deviations for MEA by Cultural Group and Gender

\begin{tabular}{lcccccc} 
& \multicolumn{2}{c}{ Males } & \multicolumn{2}{c}{ Females } & \multicolumn{2}{c}{ All } \\
\hline Institution & $\mathrm{M}$ & $\mathrm{SD}$ & $\mathrm{M}$ & $\mathrm{SD}$ & $\mathrm{M}$ & $\mathrm{SD}$ \\
University A & 3.34 & 0.97 & 3.06 & 0.97 & 3.29 & 0.95 \\
University B & 3.53 & 1.00 & 3.88 & 0.71 & 3.65 & 0.92 \\
All & 3.49 & 0.99 & 3.79 & 0.77 & 3.58 & 0.93 \\
\hline
\end{tabular}

\section{DISCUSSION}

here was a significant difference between the two universities with respect to LMA, which was a similar result found by Eccius-Wellmann et al. (2017) who found differences in mathematical anxiety between German students and Mexican engineering students that they attribute to differential beliefs and attitudes between the two cultures. This finding could lead to future research because these differences could result in a greater presence of mathematical anxiety. In Colombia, for example, low mathematical performance has been recognized nationally and internationally, which may be leading to implications in self-concept and self-efficacy when learning mathematical concepts.

On the other hand, it could also examine the usefulness that students give to learning mathematics and the expectations they have towards it, since certain beliefs about it, could be leading Colombian students to present more LMA.

The way of teaching mathematics in Colombia has not evolved much over the years, however the efforts for this methodological renewal are remarkable, even so, it continues to be a subject of great difficulty and the teaching strategies are still very focused on the 
expository with few changes towards experimentation and joint resolution of problems. Considering the technological advances to which young university students are exposed, it could be useful to incorporate technological didactic tools that motivate and arouse positive emotions in the youngest population (García-Santillán, Escalera-Chávez, Santana-Villegas, \& Guzmán-Rivas, 2016).

Significant difference existed between the two universities regarding LMA, which is contrary to Andrews and Brown (2015). Andrews and Brown (2015) found a statistically significant difference with MEA among education and nursing students with strong quantitative skills. Future research could compare different majors and the effect on LMA versus MEA. Furthermore, future research could examine why this difference existed. There was inconsistency in the responses from the participants at University A for the use of tables in the back of the book and homework with difficult problems. Is the difference related to pedagogy within the college classroom or the students' prior knowledge? This is a good question which would need further investigation to understand this background and thus be able to act from the root of the issue.

The results of this study indicated there was no difference in mathematical anxiety between males and females. García-Santillán et al. (2018), confirm a similar result in the Mexican population. Devine et al. (2012) found mathematical anxiety was a significant predictor of mathematical performance for females when checking for test anxiety. Future research could examine the effect of test anxiety on mathematical performance and mathematical anxiety.

\section{CONCLUSION}

After the presentation of the results obtained from this study and its pertinent discussion, it is time to state the conclusions that can be drawn from it:

As a general conclusion we can summarise that according to the results, mathematical anxiety is affected by cultural background, due to the fact that it affects to varying degrees according to the origin of the subject to be studied. However, when this phenomenon is analysed in more detail, it can be seen that this is only happening, according to the data in this study, with regard to LMA, where differences between the two groups have been observed. Nevertheless, the anxiety associated with learning is lower than that associated with assessment, despite the fact that in the last one no differences were found in the students of the different universities.

No differences associated with the gender of the students can be appreciated, which implies that when faced with this type of problematic situation, both groups present the same scale of anxiety, despite the fact that the symptoms are manifested in a more appreciable way by one group or another. In addition to this, and due to the great weight of the gender variable it means that when measuring the discrepancies between the two universities' students, no differences are found.

Finally, and as a striking feature that can be observed after the analysis of the AMAS, which is repeated constantly, is the greater degree of anxiety presented by subjects partici- 
pating in the study at the subscale MEA compared to LMA. This makes one wonder if the way of managing the evaluation in the different mathematical subjects is being approached in the correct way, due to the high values of anxiety that they are provoking in the students. Therefore, they should be reviewed to try to reduce this handicap and thus generate more self-confidence in them to guarantee that these tests are carried out in opitmal conditions.

Some limitations exist in this research. The sample could be amplified by overcoming the difficulties encountered in the study related to the motivation of students to participate in it. It would also be very interesting if the number of participating universities could be increased. Most of the participants, who answered the questionnaire, are men with $68.51 \%$ of the total population in the universities.

Additionally, other variables such as academic performance or individual circumstances of the students that are affecting them personally should be taken into account in future research. It is thought that future research could take into account other socio-cultural variables such as the socioeconomic level of the family, the curricular organization with which the university institution provides the teaching and learning of mathematics, particularly in different countries.

The diversity of methods for determining maths test results may be a limitation for this study. Further research is needed to determine whether the results obtained can be generalized. Therefore, future research would have to increase the sample, involving more students and universities in the study, which could also be complemented with qualitative methodologies that would give depth to the understanding of differences in learning mathematics in the two contexts.

\section{REFERENCES}

Agredo, S. M. M., Ávila Díaz, W. F., \& Grisales, M. C. (2014). Prácticas culturales y su influencia en el rendimiento académico. Plumilla Educativa, 13(1), 176-193. https://doi.org/10.30554/ plumillaedu.13.406.2014

Andrews, A., \& Brown, J. L. (2015). The effects of math anxiety. Education, 135(3), 362-370.

Bauselas-Herrera, E. (2018). PISA 2012: Anxiety and low performance in mathematical competence. Iberoamerican Journal of Diagnosis and evaluation - e Avaliação Psychological-RIDEP, 46(1), 161-173. https://doi.org/10.21865/RIDEP46.1.12

Brown, J. L., \& Sifuentes, L. M. (2016). Validation study of the abbreviated math anxiety scale: Spanish adaptation. Journal of Curriculum and Teaching, 5(2), 76-82. https://doi.org/10.5430/ jct.v5n2p76

Brown, M. B., \& Forsythe, A. B. (1974). Robust tests for the equality of variances. Journal of the American Statistical Association, 69(346), 364-367. https://doi.org/10.2307/2285659

Calvo, E. A., Cascante, L. G. M., Valdés-Ayala, Z. S., \& Quesada, S. S. (2017). Estudio de la ansiedad matemática en la educación media costarricense / Mathematical Anxiety in Secondary Education in Costa Rica. Revista Electrónica de Investigación Educativa, 19(1), 35-45. https://doi.org/10.24320/redie.2017.19.1.849

Carey, E., Hill, F., Devine, A., \& Szücs, D. (1987). The chicken or the egg? The direction of the relationship between mathematics anxiety and mathematics performance. Frontiers in Psychology, 6, 1-6. https://doi.org/10.3389/fpsyg.2015.01987 
Cerda, G., Ruiz, R. O., Casas, J. A., Rey, R., \& Pérez, C. (2016). Predisposición desfavorable hacia el aprendizaje de las Matemáticas: una propuesta para su medición. Estudios pedagógicos (Valdivia). Estudios pedagógicos (Valdivia), 42(1), 53-63. https://doi.org/10.4067/S0718 -07052016000100004

Cohen, R., \& Swerdlik, M. (2010). Psychological testing and assessment. Boston, MA: McGraw-Hill Higher Education.

Delgado, I., Espinoza, J., \& Fonseca, J. (2017). Ansiedad matemática en estudiantes universitarios de Costa Rica y su relación con el rendimiento académico y variables sociodemográficas. Propósitos y Representaciones, 5(1), 275-324. https://doi.org/10.20511/pyr2017.v5n1.148

Devine, A., Fawcett, K., Szücs, D., \& Dowker, A. (2012). Gender differences in mathematics anxiety and the relation to mathematics performance while controlling for test anxiety. Behavioral and Brain Functions, 8, 1-9. https://doi.org/10.1186/1744-9081-8-33

Eccius-Wellmann, C., Lara-Barragán, A. G., Martschink, B., \& Freitag, S. (2017). Comparison of mathematical anxiety profiles between Mexican students and German students. Ibero-American Journal of Higher Education, 8(23), 69-83. https://doi.org/10.22201/iisue .20072872e.2017.23.3011

Garbanzo-Vargas, G. M. (2016). Organizational Development and Change Processes in Educational Institutions, a Challenge for The Management of Education. Revista Educación, 1(40), 67-87. https://doi.org/10.15517/revedu.v40i1.22534

García-Santillán, A., Escalera-Chávez, M. E., Santana-Villegas, J. C., \& Guzmán-Rivas, B. Y. (2016). Estudio empírico para determinar el nivel de ansiedad hacia la matemática en estudiantes universitarios. International Journal of Developmental and Educational Psychology, 1(2), 441452. https://doi.org/10.17060/ijodaep.2016.n2.v1.545

García-Santillán, A., Martínez-Rodríguez, V., \& Santana, J. C. (2018). Psychometric Properties of the RMARS Scale in High School Students. European Journal of Contemporary Education, 7(1), 97-117. https://doi.org/10.13187/ejced.2018.1.97

Gómez-Chacón, I. M. (2010). Actitudes de los estudiantes en el aprendizaje de la matemática con tecnología. Enseñanza de Las Ciencias, 28(2), 227-244. https://doi.org/10.5565/rev/ec/v28n2 .197

Hopko, D. R., Mahadevan, R., Bare, R. L., \& Hunt, M. K. (2003). The abbreviated math anxiety scale (AMAS): Construction, validity, and reliability. Assessment, 10(2), 178-182. https://doi.org/ $10.1177 / 1073191103010002008$

ICFES. (2017). National results report. Colombia in PISA 2015. Bogotá, Colombia: Colombian Institute for Educational Evaluation.

Isiksal, M., Curran, J. M., Koc, Y., \& Askun, C. S. (2009). Mathematics anxiety and mathematical self-concept: Considerations in preparing elementary-school teachers. Social Behavior and Personality, 37(5), 631-643. https://doi.org/10.2224/sbp.2009.37.5.631

Jácquez, L. F. H. (2018). Perfil sociodemográfico y académico en estudiantes universitarios respecto a su autoeficacia académica percibida. Psicogente, 21(39), 35-49. https://doi.org/10.17081/ psico.21.39.2820

Justicia-Galiano, M. J., Pelegrina, S., Lechuga, M. T., Gutiérrez-Palma, N., Martín-Puga, E. M., \& Lendínez, C. (2016). Math anxiety and its relationship to inhibitory abilities and perceived emotional intelligence / Ansiedad matemática y su relación con capacidades inhibitorias e inteligencia emocional percibida. Anales de Psicología, 1, 125-125. https://doi.org/10.6018/ analesps.32.1.194891

Kastberg, D., Chan, J. Y., Murray, G., \& Gonzales, P. (2016). Performance of U.S. 15-year-old students in science, reading, and mathematics literacy in an international context: First look at PISA 2015 (NCES 2017-048). Retrieved from https://nces.ed.gov/pubs2017/2017048.pdf 
Maloney, E. A., Schaeffer, M. W., \& Beilock, S. L. (2013). Mathematics anxiety and stereotype threat: shared mechanisms, negative consequences and promising interventions. Research in Mathematics Education, 15(2), 115-128. https://doi.org/10.1080/14794802.2013.797744

Marshall, G. (2000). Explaining mathematics anxiety in college students. A research project. The Mathematics Educator, 5(1/2), 108-116.

Mehdinezhad, V., \& Bamari, Z. (2015). The Relationship between Test Anxiety, Epistemological Beliefs and Problem Solving among Students. Journal of New Approaches in Educational Research, 4(1), 2-8. https://doi.org/10.7821/naer.2015.1.97

NCTM. (2003). Principios y estándares para la educación matemática. USA: Reston.

O'Leary, K., Fitzpatrick, C. L., \& Hallett, D. (2017). Math anxiety is related to some, but not all, experiences with math. Frontiers in Psychology, 8, 1-14. https://doi.org/10.3389/fpsyg.2017 .02067

Pérez-Tyteca, P. (2012). La ansiedad matemática como centro de un modelo causal predictivo de la elección de carreras (Doctoral dissertation). Retrieved from http://hdl.handle.net/10481/ 23293

Pérez-Tyteca, P., Castro, E., Rico, L., \& Castro, E. (2011). Mathematical anxiety, gender and knowledge branches in university students. Science Teaching: Journal of Research and Didactic Experiences, 29(2), 237-250. https://doi.org/10.5565/rev/ec/v29n2.570

Pérez-Tyteca, P., Monk, J., \& Castro, E. (2013). Affection and mathematics. Design an interview to access the feelings of adolescent students. Research Advances in Mathematical Education, 4, $65-82$.

Reali, F., Jimenez-Leal, W., Maldonado-Carreño, C., Devine, A., \& Szücs, D. (2016). Examining the link between mathematical anxiety and mathematical performance in Colombian students. Revista Colombiana de Psicologia, 25(2), 369-379. https://doi.org/10.15446/rcp

Rodic, M., Cui, J., Malykh, S., Zhou, X., Gynku, E. I., Bogdanova, E. L., ... ., Y. (2018). Cognition, emotion, and arithmetic in primary school: A cross-cultural investigation. British Journal of Develepmental Psychology, 36, 255-276. https://doi.org/10.1111/bjdp.12248

Solà, N. G., Planas, N., \& Vilella, X. (2000). Cultura y educación matemática. . Cuadernos de pedagogía, 288, 72-75.

Suárez, J. G., Perez-Tyteca, P., \& Monje, J. (2018). La utilidad de las matemáticas desde la perspectiva de futuros ingenieros mexicanos del Centro Universitario de la Costa Sur. In R. Roig-Vila (Ed.), El compromiso académico y social a través de la investigación e innovación educativas en la Enseñanza Superior (pp. 213-223). Barcelona: Octaedro. 